Textures and Microstructures, Vol. 33, pp. 13-33

Reprints available directly from the publisher

Photocopying permitted by license only
(C) 1999 OPA (Overseas Publishers Association) N.V.

Published by license under the Gordon and Breach Science

Publishers imprint.

Printed in Malaysia.

\title{
ADVANCES AND APPLICATIONS OF NEUTRON TEXTURE ANALYSIS
}

\author{
H.-G. BROKMEIER \\ Department of Physical Metallurgy, Technical University Clausthal and \\ GKSS Research Center, Max-Planck-Str. Geb.03, \\ D-21502 Geesthacht, Germany
}

\begin{abstract}
Due to the high penetration depth of thermal neutrons for most materials, neutron diffraction is an efficient tool for bulk texture analysis. The main applications are investigations of coarse-grained materials, non-destructive pole figure measurements of identical samples at different states, detection of weak textures, measurement of unprepared samples and texture investigations of multi-phase systems. It should be pointed out that neutron texture analysis is suitable for basic research as well as for applications.
\end{abstract}

Keywords: Bulk texture; Neutron diffraction; Pole figure measurement; Multi-phase materials; Non-destructive investigations

\section{INTRODUCTION}

Texture analysis by means of neutron diffraction is one of the standard methods in modern texture analysis. Since the first neutron diffraction texture measurement carried out by Brockhouse (1953) a number of improvements have been made. This includes instrumental developments, methodical improvements and of course mathematical approaches for a quantitative texture analysis. Different authors have published these improvements from time to time with a concentration to different topics. The following list gives only a brief collection of some important papers: neutron texture analysis (Szpunar, 1976; Welch, 1986; Bunge, 1989; Brokmeier, 1994); instrumentation (Feldmann, 1989; Hansen et al., 1981; Bunge et al., 1982; Wenk et al., 1988); quantitative texture analysis (Bunge, 1969; Matthies et al., 1987; Schaeben, 1988). 
Looking on diffraction methods to measure textures of a sample volume with a statistical arrangement of crystallites mainly three different radiations are in use. These are $X$-rays produced by a conventional $\mathrm{X}$-ray tube or by a synchrotron, electrons and thermal neutrons. The differences of these radiations are based on the interaction of the radiation with matter (see Bacon, 1975; Cullity, 1956). Focusing to texture measurements the main differences between X-rays, electrons and neutrons are the penetration depth, the local sample volume and the global sample volume, (see Table I). It must be pointed out that Table I is given for a high number of conventional materials. But the enormous variety of materials having large differences in the scattering behavior cannot be taken into account completely. Thus, the applicability of new materials has to be estimated individually.

According to the more physical differences there are practical differences such as the availability and the costs. Methods needing a large scale facility like a neutron beam or a high energetic X-ray beam are limited in the number of sources, in the number of instruments and of course in the availability of beam time. Based on the properties shown in Table I electron diffraction is favored in microtexture analysis. The standard method for texture analysis is the use of conventional X-rays. Recent improvements particularly in new X-ray optics and new detector systems have enlarged the efficiency and the accuracy of the standard X-ray techniques. Nevertheless the high penetration depth is necessary for a lot of problems particularly in global texture analysis and in local texture analysis inside a bulk. Compared to high energetic X-rays neutron diffraction texture analysis is a well-established method available in most of the neutron research centers worldwide with a high number of applications on different materials. In future new developments in high energetic X-rays will overcome some neutron applications which are limited by the beam flux and the lack of a local resolution in sample volume.

TABLE I Comparison of neutrons, X-rays and electrons

\begin{tabular}{|c|c|c|c|c|}
\hline & Neutrons & $\begin{array}{c}X \text {-rays } \\
\text { (conventional) }\end{array}$ & $\begin{array}{c}X \text {-rays } \\
\text { (synchrotron) }\end{array}$ & Electrons \\
\hline Penetration depth & $10-40 \mathrm{~mm}$ & $10^{-1}-10^{-2} \mathrm{~mm}$ & $10^{1}-10^{-2} \mathrm{~mm}$ & $10^{-4} \mathrm{~mm}$ \\
\hline $\begin{array}{l}\text { Local sample } \\
\text { volume }\end{array}$ & $10^{9} \mu \mathrm{m}^{3}$ & $10^{6} \mu \mathrm{m}^{3}$ & $10^{3} \mu \mathrm{m}^{3}$ & $10^{-6} \mu \mathrm{m}^{3}$ \\
\hline $\begin{array}{l}\text { Global sample } \\
\text { volume }\end{array}$ & $10^{2}-10^{4} \mathrm{~mm}^{3}$ & $10^{-6}-10^{-1} \mathrm{~mm}^{3}$ & $10^{-6}-10^{3} \mathrm{~mm}^{3}$ & $10^{-10}-10^{-16} \mathrm{~mm}^{3}$ \\
\hline
\end{tabular}




\section{NEUTRON DIFFRACTION}

The principles of neutron diffraction are the same as those for X-ray diffraction. Therefore, neutron diffraction methods for texture analysis are closely parallel to well-known X-ray diffraction techniques. But owing to the high penetration depth of neutrons there are some typical advantages of neutrons against conventional X-rays. Table II shows the penetration depth of some minerals for neutron $(1.00 \AA)$, for $\mathrm{Cu} \mathrm{K} \alpha-\mathrm{X}$ rays $(1.54 \AA)$ and for high energetic X-rays $(0.21 \AA)$.

Compared to $1.54 \AA \mathrm{X}$-rays, neutrons have in all cases a much higher penetration depth even for epsomite, a mineral with a high water content. Neutrons and $0.21 \AA$ X-rays have penetration depths in the same order but show some remarkable differences. Hematite, an iron oxide has a relatively high penetration for neutrons while epsomite has a relatively high penetration depth for $0.21 \AA \mathrm{X}$-rays. This behavior correlates to the presence of heavy atoms, light atoms and hydrogen in the material. According to this relatively high penetration a number of advantages result which will be discussed in detail later.

A second difference between neutrons and X-rays is that the atomic scattering amplitude for neutrons is independent on one hand on the scattering angle $2 \theta$ and on the other hand on the atomic number. Consequently, the diffraction patterns obtained by neutrons or $\mathrm{X}$-rays are different. Light atoms contribute in the same order as heavy atoms on neutron scattering. In the case of calcite and corundum the basal plane pole figure can be measured with neutrons but virtually not with conventional X-rays due to the low scattering factor for X-rays. Moreover, high order reflections ((400), (440), (444)) can be measured using neutrons with nearly the same order of intensities as low indexed reflections

TABLE II Comparison of the penetration depth $d_{1 / 2}$ (in $\mathrm{cm}$ )

\begin{tabular}{lccc}
\hline Material & Neutrons $(\lambda=1.00 \AA)$ & $X$-rays $(\lambda=1.54 \AA)$ & $X$-rays $(\lambda=0.21 \AA)$ \\
\hline Hematite & 4.33 & 0.0006 & 0.14 \\
Albite & 2.48 & 0.0081 & 1.03 \\
Anhydrite & 2.39 & 0.0032 & 0.58 \\
Quartz & 2.39 & 0.0076 & 1.00 \\
Calcite & 1.98 & 0.0036 & 0.64 \\
Halite & 0.82 & 0.0042 & 0.85 \\
Gypsum & 0.24 & 0.0049 & 0.82 \\
Epsomite & 0.14 & 0.0175 & 1.73 \\
\hline
\end{tabular}


((200), (110), (111)). A very special situation is given for tetragonal $\gamma$ TiA1 (see Fig. 1). According to the crystal structure $P 4 / \mathrm{mmm}$ there are two sets of reflections detectable by X-rays. Strong reflections will be obtained in the case of adding the contributions of titanium and aluminium ((111), (002)/(200), (202)/(220)) while the second set of
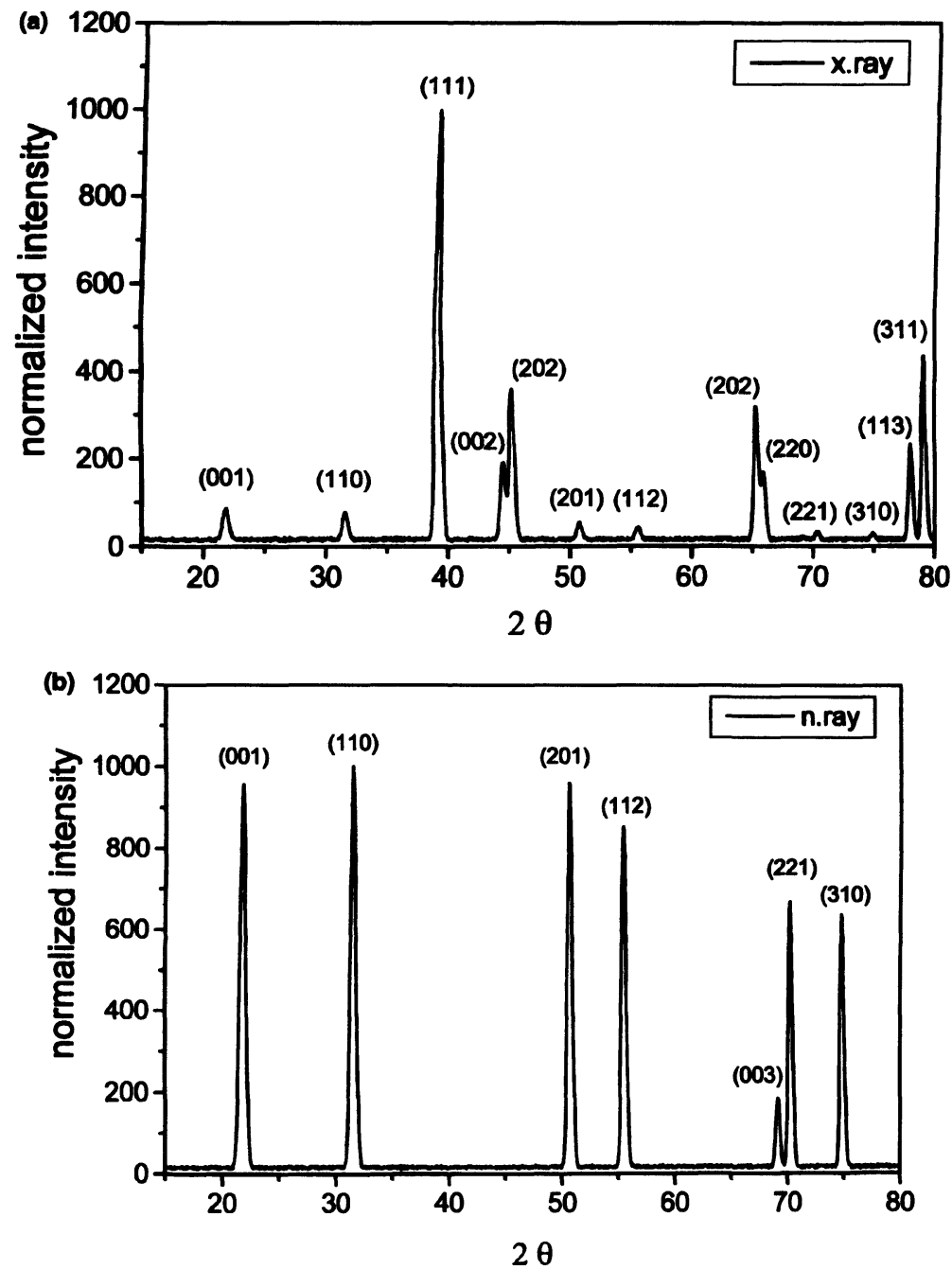

FIGURE 1 Diffraction pattern of TiAl using (a) $1.5 \AA$ neutrons; (b) $1.5 \AA$ X-rays. 
reflections by subtracting yields very low scattered intensities. In the case of neutron diffraction it is opposite because of the scattering amplitudes for aluminium $\left(b_{\mathrm{Al}}=0.345 \mathrm{~cm}^{-12}\right)$ and titanium $\left(b_{\mathrm{Ti}}=-0.337 \mathrm{~cm}^{-12}\right)$ respectively. That means the strong reflections using neutrons are (001), (110), (201) and (112), which cannot be measured by X-rays.

\section{POLE FIGURE MEASUREMENT}

One of the main advantages of neutron measurements is the use of the spherical sample method after Tobisch and Bunge (1972) to get complete pole figures. This method allows the measurement of the average texture of samples with some $\mathrm{cm}^{3}$ in volume and a background correction only. Depending on the high transmission absorption corrections can be neglected not only in spherical samples but also in cylinders and cubes. Thus pole figures can be measured non-destructively of non-uniform samples as shown in Fig. 2.

The scanning routines to measure pole figures are closely parallel to Xray measurements. Figure 3 shows two typical counting grids to cover complete pole figures.

Instrumental improvements and increasing availability of new instruments have optimized the present situation of neutron texture analysis. The following methods of pole figure measurements by neutrons are in operation and open for the user community.

\begin{tabular}{ll}
\hline $\begin{array}{l}\text { Four circle diffractometer with } \\
\text { a single detector }\end{array}$ & $\begin{array}{c}\text { One pole figure point for each } \\
\text { measurement each pole figure } \\
\text { separately }\end{array}$ \\
$\begin{array}{l}\text { Four circle diffractometer with } \\
\text { position sensitive detector in } \\
\text { horizontal geometry }\end{array}$ & $\begin{array}{l}\text { One pole figure point for each } \\
\text { measurement position a number } \\
\text { of pole figures simultaneously } \\
(\alpha, \beta \text {-transformation) }\end{array}$ \\
$\begin{array}{c}\text { Four circle diffractometer with } \\
\text { position sensitive detector in } \\
\text { vertical geometry }\left(2 \theta-90^{\circ}\right)\end{array}$ & $\begin{array}{l}\text { A number of pole figure points } \\
\text { simultaneously each pole } \\
\text { figure separately }\end{array}$ \\
\hline
\end{tabular}




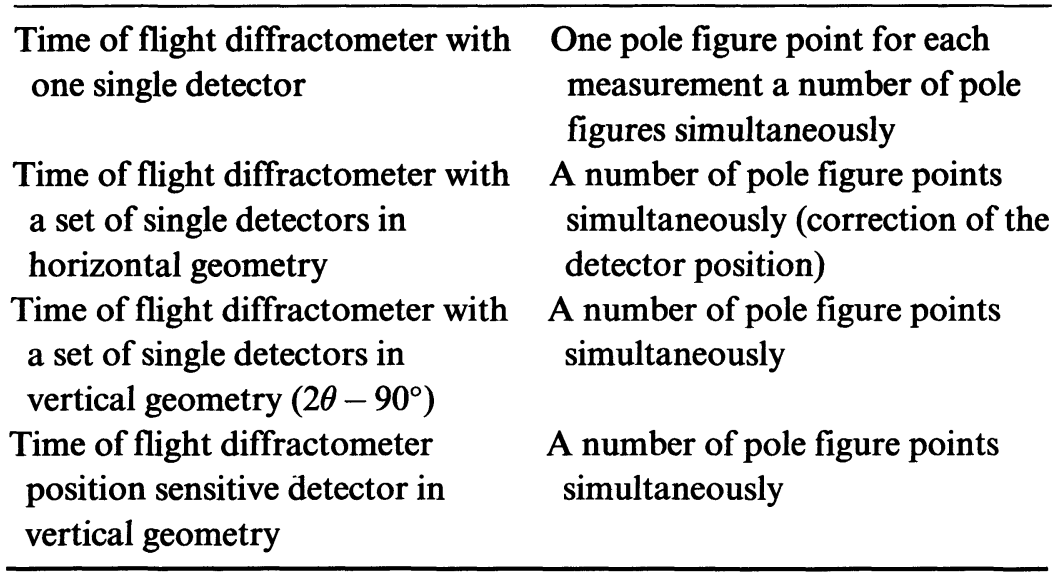

It must be pointed out that the availability of these methods is close connected to the instrumentation. A four circle diffractometer with a single detector belongs to the standard instrumentation of all research centers but the additional detector systems are restricted to some places worldwide.

\section{ADVANTAGES OF NEUTRON DIFFRACTION}

As pointed out above the main advantages arise from the high penetration of neutrons. The investigated sample volume in neutron diffraction texture measurement is $10^{4}-10^{6}$ times higher than in the case of $\mathrm{X}$-rays. Thus neutron diffraction is an efficient tool for global texture investigations. The measurement of large sample volumes in the order of some $\mathrm{cm}^{3}$ gives on one hand the possibility to analyze coarse-grained materials and on the other hand to increase the grain statistics in finegrained materials. Moreover, in the case of inhomogeneous textures an averaging takes place and texture can be correlated very well to mechanical testing carried out at similar sample volumes.

A second advantage is the sample preparation. The main step of sample preparation is to fix the sample on a sample holder. A surface preparation such as polishing is not necessary because a surface roughness of some $\mathrm{mm}$ has no important influence on the accuracy of the measurement. The ideal neutron sample is a sphere, to have no 

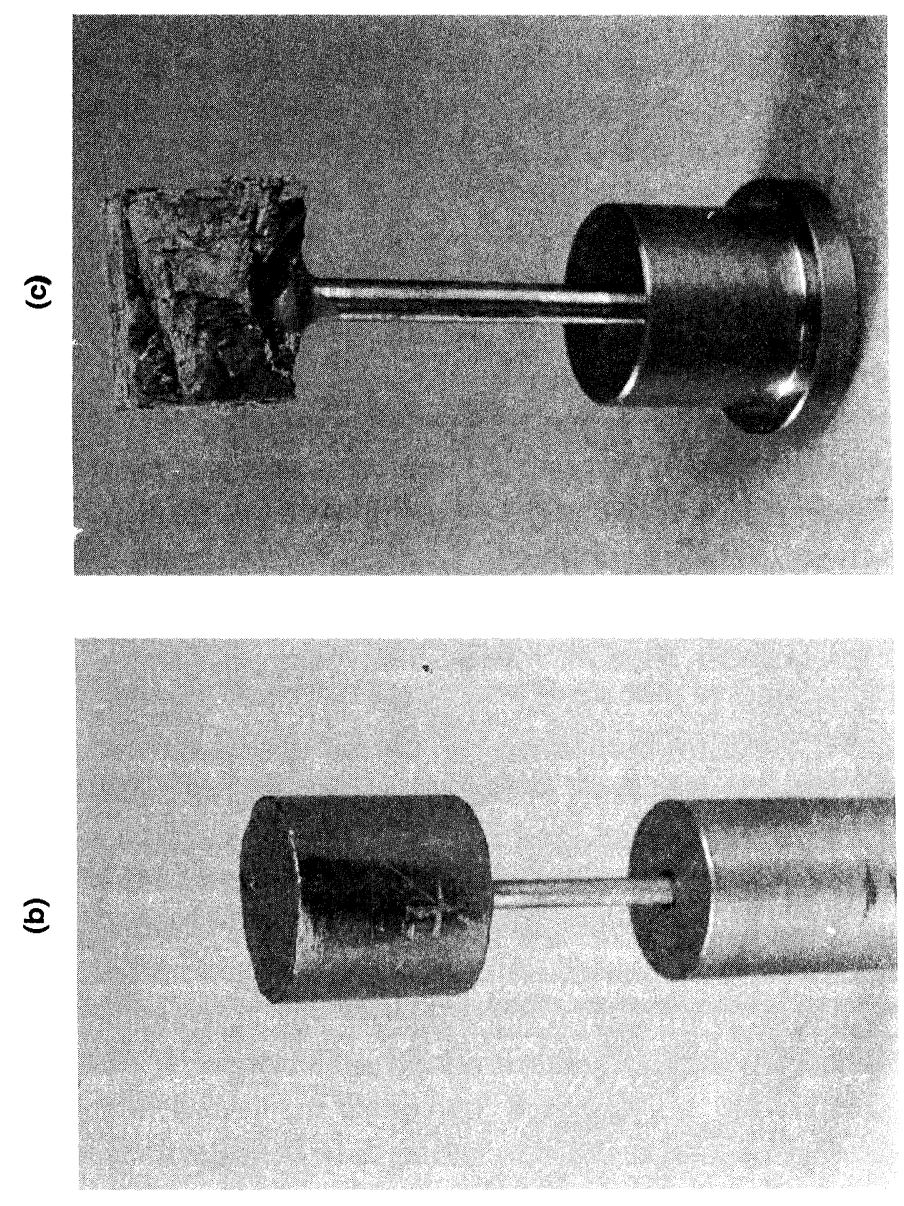

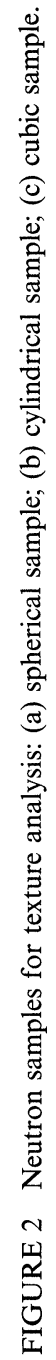

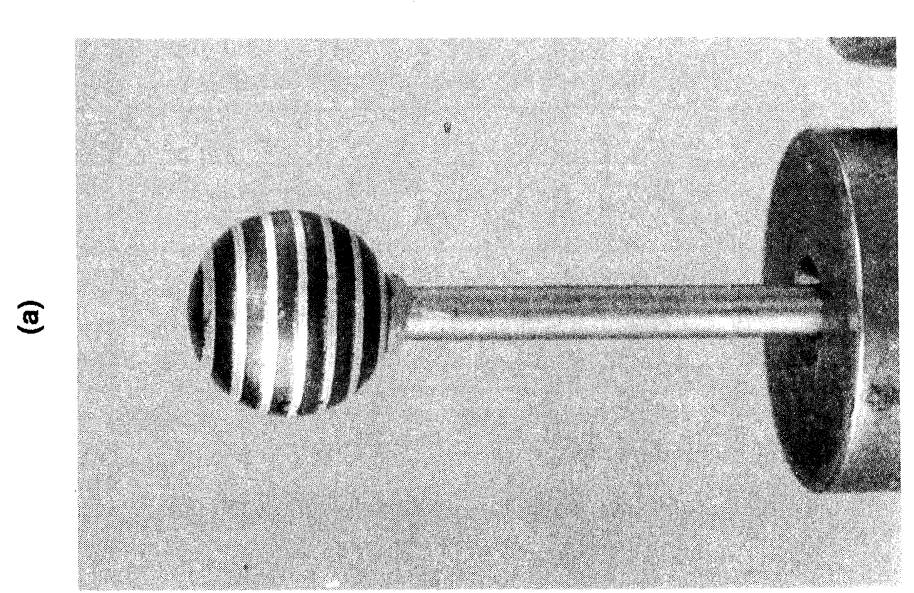



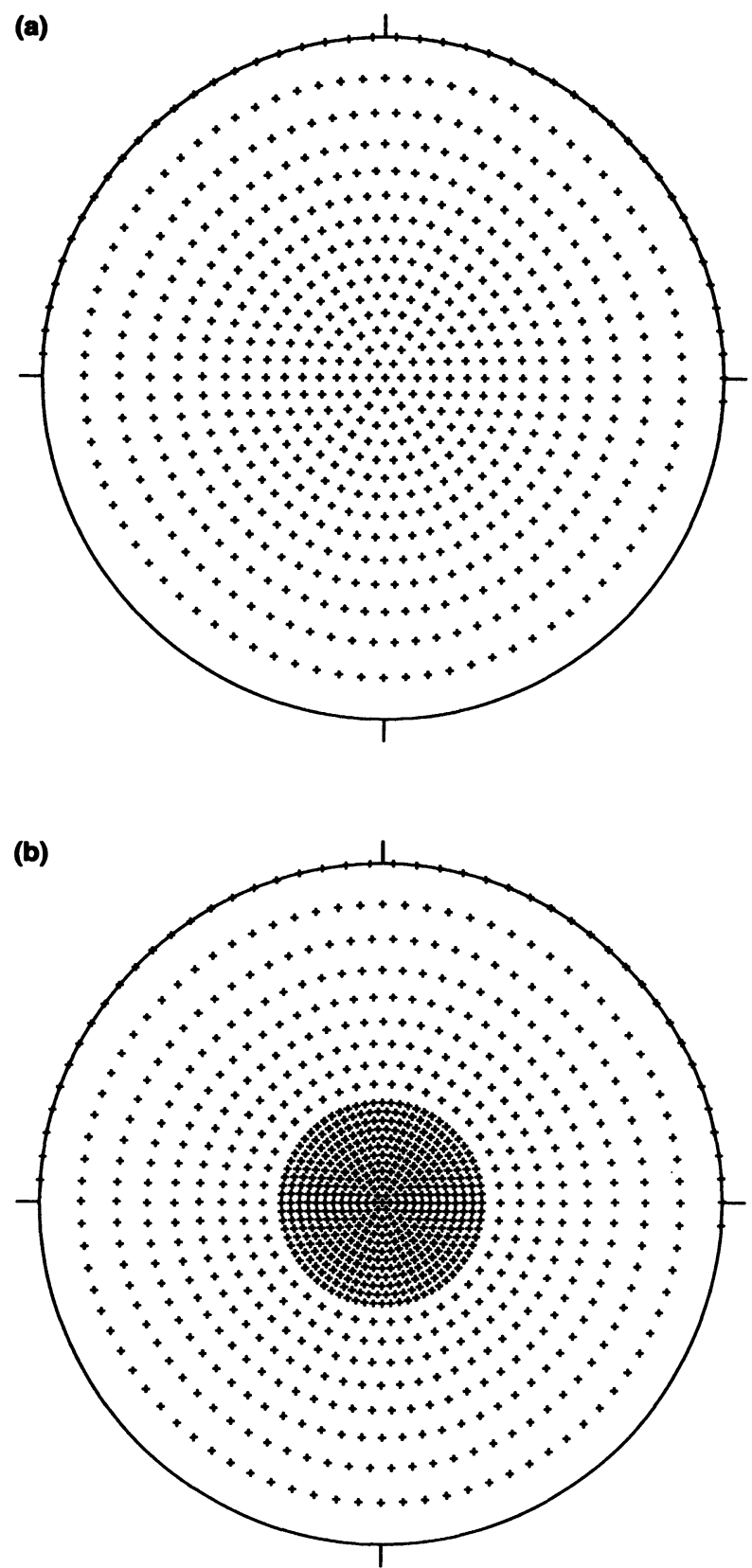

FIGURE 3 Counting grid for a complete pole figure measurement: equal area scan with (a) 679 pole figure; (b) two different resolutions. 
anisotropic absorption. But most materials show a rather high penetration depth (Brokmeier, 1995) so that the measurement of cylindrical or of cubic samples gives the same accuracy as spherical samples. Therefore in practice cubic and spherical samples are preferred because of the simpler sample preparation. Figure 4 shows the typical sample preparation. A calcite cylinder of $20 \mathrm{~mm}$ in diameter was fixed in an adjustment unit to glue a vanadium pin. In order to increase the sample volume of highly deformed materials it is possible to compact sheet sections or segments of a wire. An increased sample volume reduces the total counting time particularly in thin samples. Figure 5 shows a compacted cubic sample glued on a vanadium pin already fixed in a sample holder.

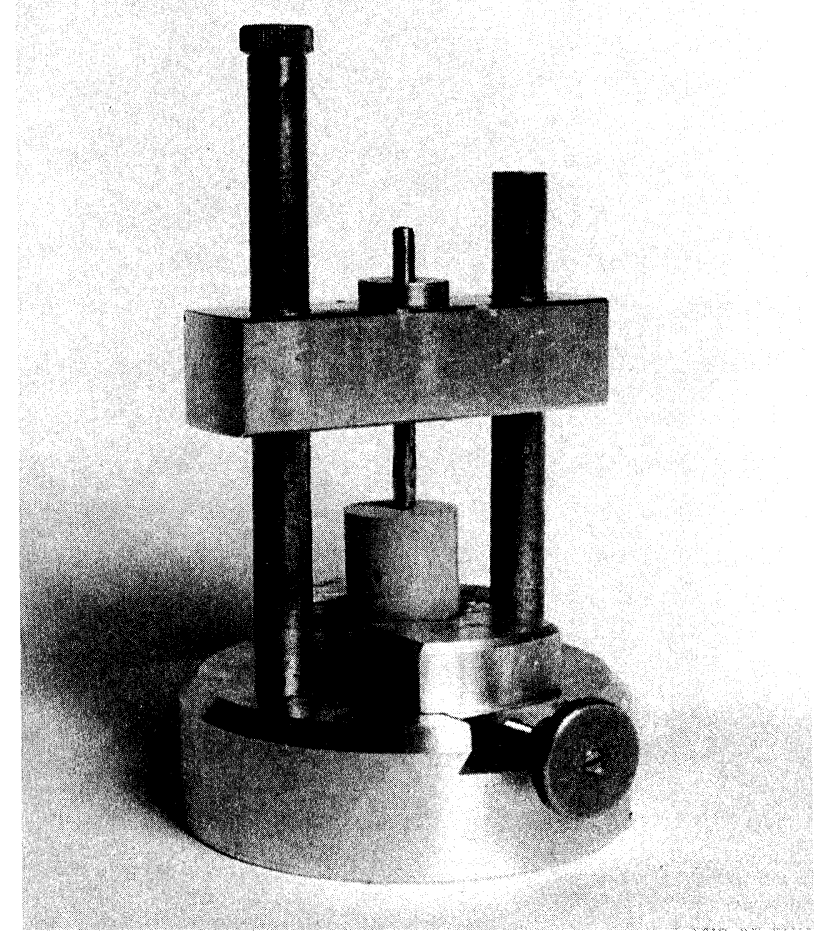

FIGURE 4 Calcite cylinder on an adjustment unit to fix a vanadium pin. 


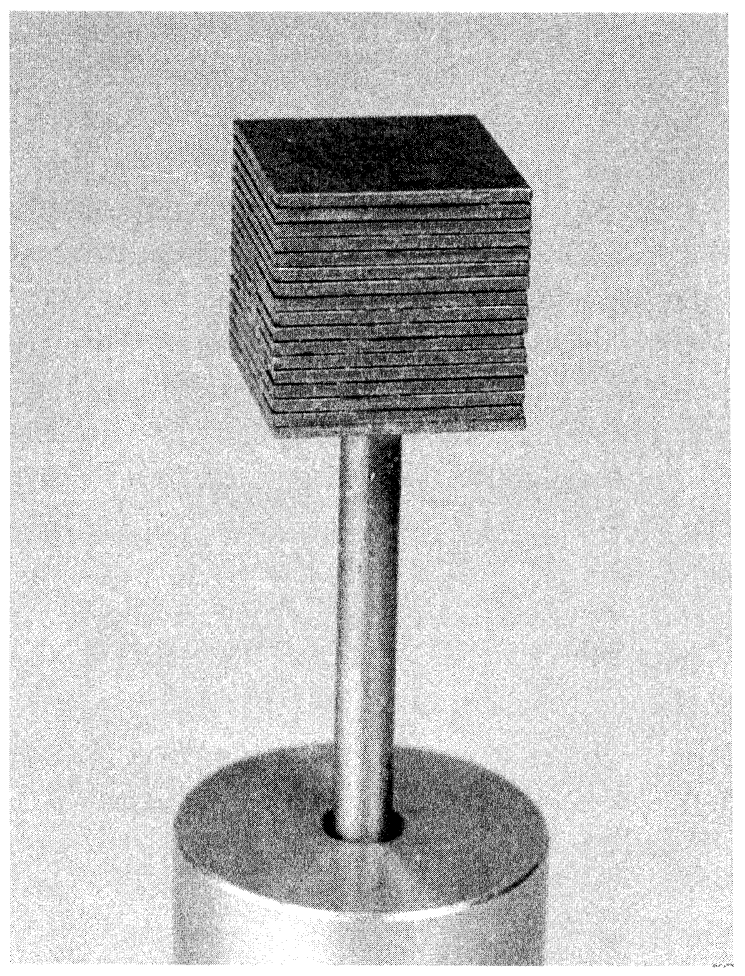

FIGURE 5 Compacted cubic sample.

The high penetration allows the measurement of local textures at the sample surface as well as inside a compact sample. This method is based on the usage of two cadmium slits as described first by Choi et al. (1979) to cover a well-defined sample volume. The main restriction is given by the minimum sample volume which is necessary to get a sufficient peak to background ratio. This is due to a relatively low intense neutron beam. In contrast to a standard neutron beam a synchrotron beam is much more powerful so that most of all local texture measurements carried out today by neutrons will be overcome in a near future by synchrotron experiments.

More efficient for the application of neutrons is the non-destructive measurement in order to analyze a sample at different states such as:

- as received $\rightarrow$ forging or hammering

- as received $\rightarrow$ deformation $\rightarrow$ annealing 
- as received $\rightarrow$ low cycling (first step) $\rightarrow$ low cycling (second step) $\rightarrow \cdots$

Figure 6(a) shows the (102) chalkopyrite pole figure of the starting material whereas Figure 6(b) shows the (102) pole figure of the sample after experimental deformation (Jansen et al., 1995).

In geoscience as well as in recent developments in material science more and more multi-phase systems have to be characterized. The main differences between single-phase and multi-phase systems are:

- a reduction of the volume fraction;

- each phase has its own texture;

- overlapping of different phases;

- textures are very often weaker in a multi-phase material;

- multi-phase systems are more often inhomogeneous.

Looking on these differences some practical consequences result. First is that the total counting time for an investigation of a multi-phase

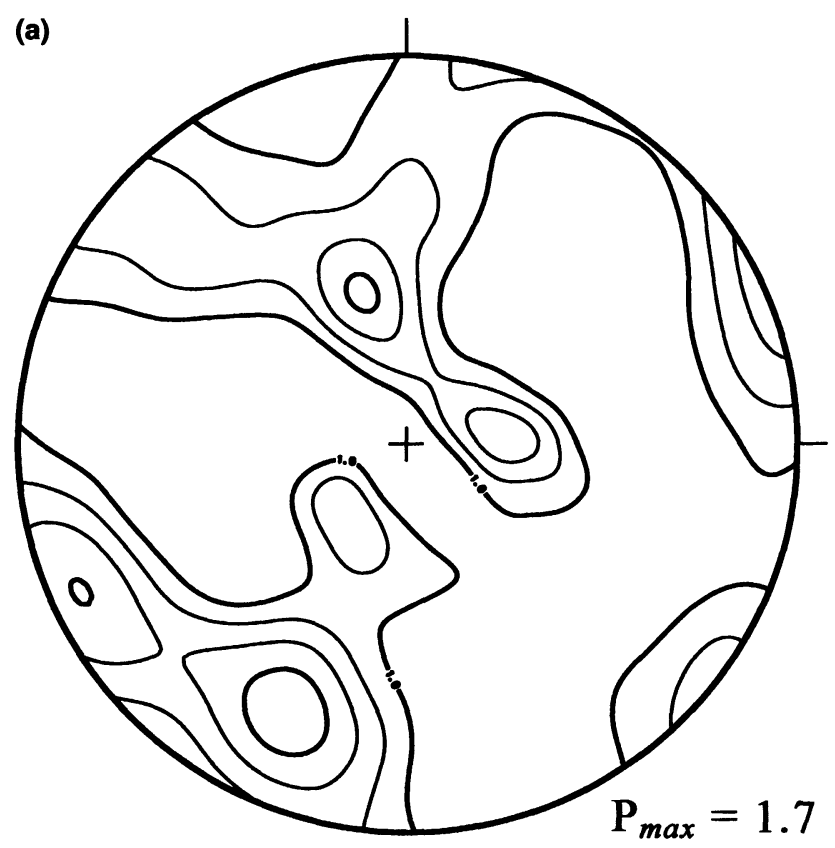

FIGURE 6(a) 


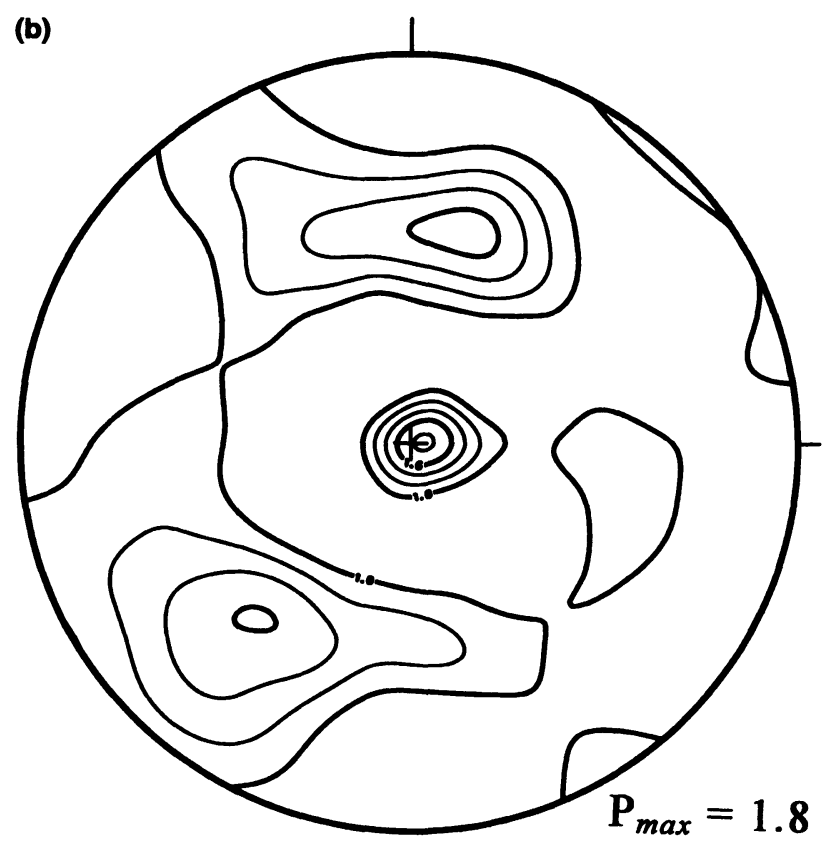

FIGURE 6(b)

FIGURE $6 \mathrm{CuFeS}_{2}$ (102) pole figure (a) before experimental deformation; (b) after experimental deformation.

material is much longer than for single-phase material. Due to the lower volume fraction this applies also if only the majority phase is investigated. The minimum volume fraction which is necessary to have a sufficient peak to background ratio depends strongly on the scattering behavior. In the case of copper in aluminium volume fraction of lower than $1 \%$ copper is sufficient (Brokmeier and Bunge, 1987). Second is an increasing overlapping for multi-phase materials. Particularly in rocks with more than four or five phases having low crystal symmetry overlapping is a current problem. Among others the experimental conditions can help to solve overlapping problems. Table III shows a comparison between the number of Bragg-reflections for $\mathrm{Al}$ and $\mathrm{Al}_{2} \mathrm{O}_{3}$ and different wavelengths. Both materials are very common and not very complicated to measure. It must be pointed out that the number of Bragg-reflections includes total overlapping such as 113 and 11-3 for corundum. In the case of cubic aluminium two or three pole figures are sufficient for a 
TABLE III Number of Bragg-reflections for different radiations in the first $90^{\circ}$ in $2 \theta\left(20^{\circ}\right.$ in $\left.2 \theta\right)$

\begin{tabular}{lcccccc}
\hline Radiation & $\lambda$ & \multicolumn{2}{c}{$A l$} & & \multicolumn{2}{c}{$\mathrm{Al}_{2} \mathrm{O}_{3}$} \\
\cline { 3 - 6 } \cline { 6 - 7 } & $(\AA)$ & $0-90^{\circ} 2 \theta$ & $0-20^{\circ} 2 \theta$ & & $0-90^{\circ} 2 \theta$ & $0-20^{\circ} 2 \theta$ \\
\hline $\mathrm{Cr} \mathrm{K} \alpha$ & 2.2909 & 1 & - & & 8 & - \\
$\mathrm{Cu} \mathrm{K} \alpha$ & 1.5418 & 5 & - & 38 & - \\
$\mathrm{Mo} \mathrm{K} \alpha$ & 0.7107 & 26 & 1 & 417 & 6 \\
$\mathrm{Ag} \mathrm{K} \alpha$ & 0.5609 & 48 & 2 & 865 & 8 \\
$\mathrm{~W} \mathrm{~K} \alpha$ & 0.2090 & 604 & 18 & $2729\left(45^{\circ}\right)$ & 231 \\
Neutrons & 1.0000 & 11 & - & & 107 & 1 \\
Neutrons & 1.3300 & 6 & - & 59 & - \\
Neutrons & 2.3000 & 2 & - & 7 & - \\
\hline
\end{tabular}

quantitative texture analysis while trigonal $\mathrm{Al}_{2} \mathrm{O}_{3}$ needs between four and six pole figures at minimum. $\mathrm{Cr} \mathrm{K} \alpha, \mathrm{Cu} \mathrm{K} \alpha, \mathrm{MoK} \alpha$ and $\mathrm{Ag} \mathrm{K} \alpha$, are standard radiations of common X-ray tubes. A short wavelength like molybdenum and silver shows rather high numbers of reflections mainly used for crystal structure analysis and not for texture analysis. Due to high energetic $\mathrm{X}$-rays with a penetration comparable to neutrons a wavelength of about $0.2 \AA$ (such as $\mathrm{W} \mathrm{K} \alpha$ ) gives a very high number of Bragg-reflections. In the case of cubic materials this is no problem, in the case of low symmetric materials it is a remarkable problem, and in the case of a multi-phase rock (amphibolite, lherzolithe etc.) a very heavy problem. The three neutron wavelengths given in Table III are available at TEX-2 (GKSS-Research Center) using different monochromators and different monochromator take-off angles. That means, the neutron beam can be optimized to help for deconvolution of overlapping.

Another point of interest is the possibility to use a containment. A number of applications have been carried out to use different types of containments such as a furnace (Juul Jensen, 1992), a cryostat (Elf $e t$ al., 1990) or even a box to save light-sensitive materials (Ewald, 1986). Even in the case of very brittle sediments an aluminium box is very helpful in order not to destroy the sample.

One important application of neutron diffraction is the nondestructive texture analysis of non-uniform samples as shown in Fig. 7. Figure 7(a) shows a standard sample for a tensile test. In the case of such a sample it is possible on one hand to investigate the local texture of different parts of the sample and on the other hand to carry out a low cycle experiment measuring the texture at identical sample positions. 
(a)
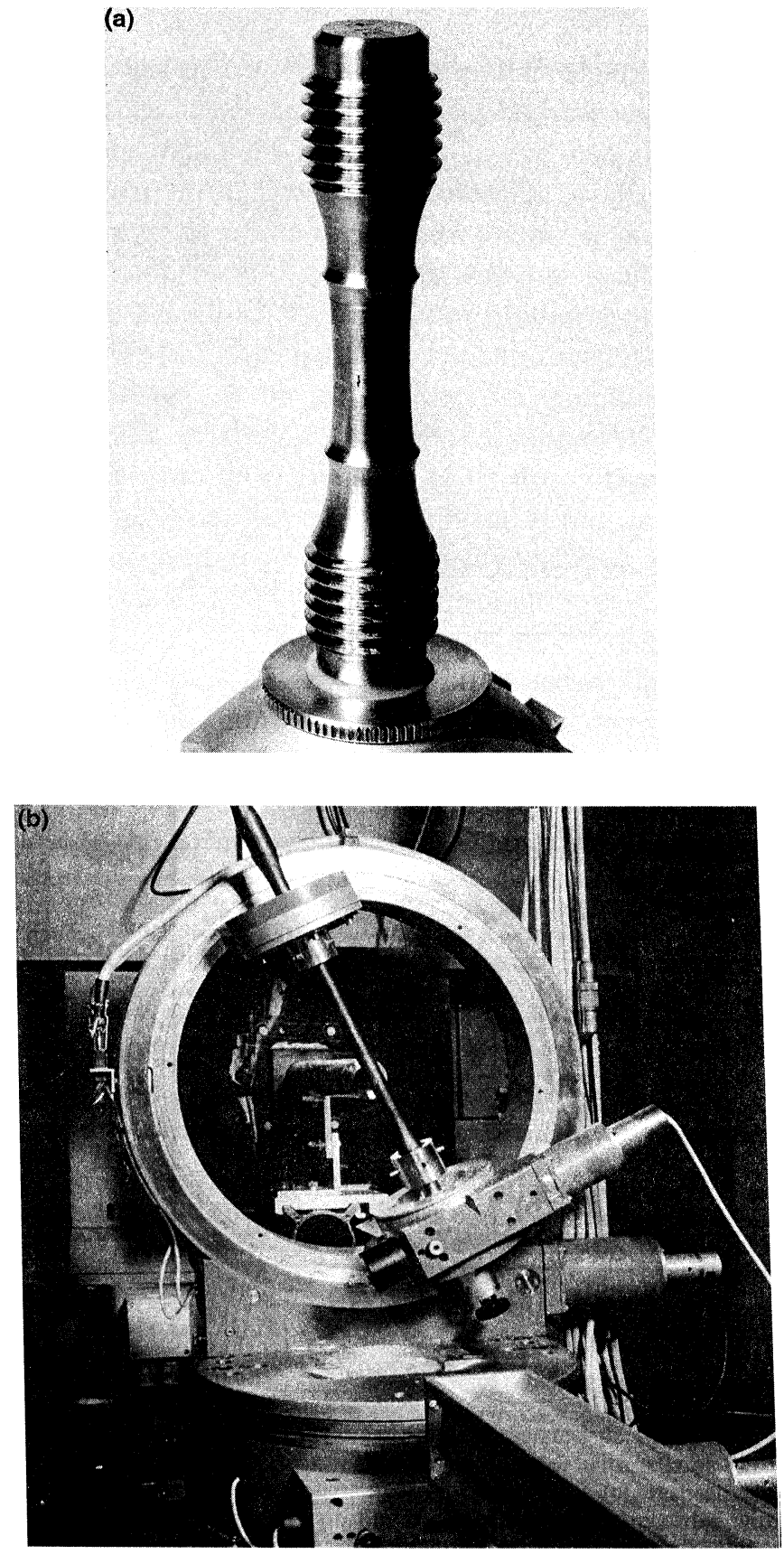

FIGURE 7 (a) Standard tensile sample to measure the texture non-destructively by neutrons. (b) Spring steel mounted in the Eulerian cradle. 
A second example of a non-uniform sample is a spring steel shown in Fig. 7(b). Samples of $30 \mathrm{~mm}$ thicknesses and up to $1000 \mathrm{~mm}$ in length were investigated to look on texture inhomogeneities.

\section{APPLICATIONS}

Since the first texture measurements using neutrons on nickel alloy in 1953 numerous investigations were carried out. This brief collection of some typical neutron applications will focus on TEX-2 measurements. It should be noticed that TEX-2 is a standard four circle diffractometer optimized for texture analysis. That means, between 200-300 samples were measured every year at TEX-2. One of the consequences is that sets of up to 40 individual samples and more for one project can be measured, (see Table IV).

Example 1: YBaCuO-cylinders Among others the effective magnetic levitation force of melt-grown YBaCuO-cylinders depends strongly on the crystallographic texture (Bornemann et al., 1996). The deviation of the $c$-axis distribution from the cylinder axis should be within $5^{\circ}$ with a spread of less than $5^{\circ}$. Neutron diffraction is indicated because of the coarse-grained material to get a sufficient grain statistics. Figures 8(a) and 8(b) show two examples of the extensive studies. In Fig. 8(a) a partial pole figure of only the central part demonstrates the orientation of the (005) distribution to the cylinder axis. Figure 8(b) shows the local texture of a $\mathrm{YBaCuO}$ cylinder with $43 \mathrm{~mm}$ in diameter and $15 \mathrm{~mm}$ in height which was cut into rectangular pieces (Jung et al., 1998). The local texture analysis of the whole $\mathrm{YBaCuO}$

TABLE IV Selected list of projects having a set of samples

\begin{tabular}{lllc}
\hline Project & \multicolumn{1}{c}{ User } & \multicolumn{1}{c}{ Institute } & Samples \\
\hline Fe-Cu composites & $\begin{array}{l}\text { Opoku/Reinert/ } \\
\text { Brokmeier/Bunge }\end{array}$ & IMM-TU Clausthal & 72 \\
Galena & Jansen/Siemes & RWTH Aachen & 45 \\
Pass rolling metals & Schneider/Klimanek & TU-BA-Freiberg & 44 \\
Rock-salt & Skrotzki/Dornbusch & TU Dresden/ & 44 \\
Chalkopyrite & Jansen/Siemes & IGDL Göttingen & \\
Al-Cu composites & Gertel-Kloos/Brokmeier & IMMH Aachen & 38 \\
YBaCuO & Jung & FZ Karlsruhe & 31 \\
Ti-alloys & Gregory & GKSS-WD & 31 \\
\hline
\end{tabular}



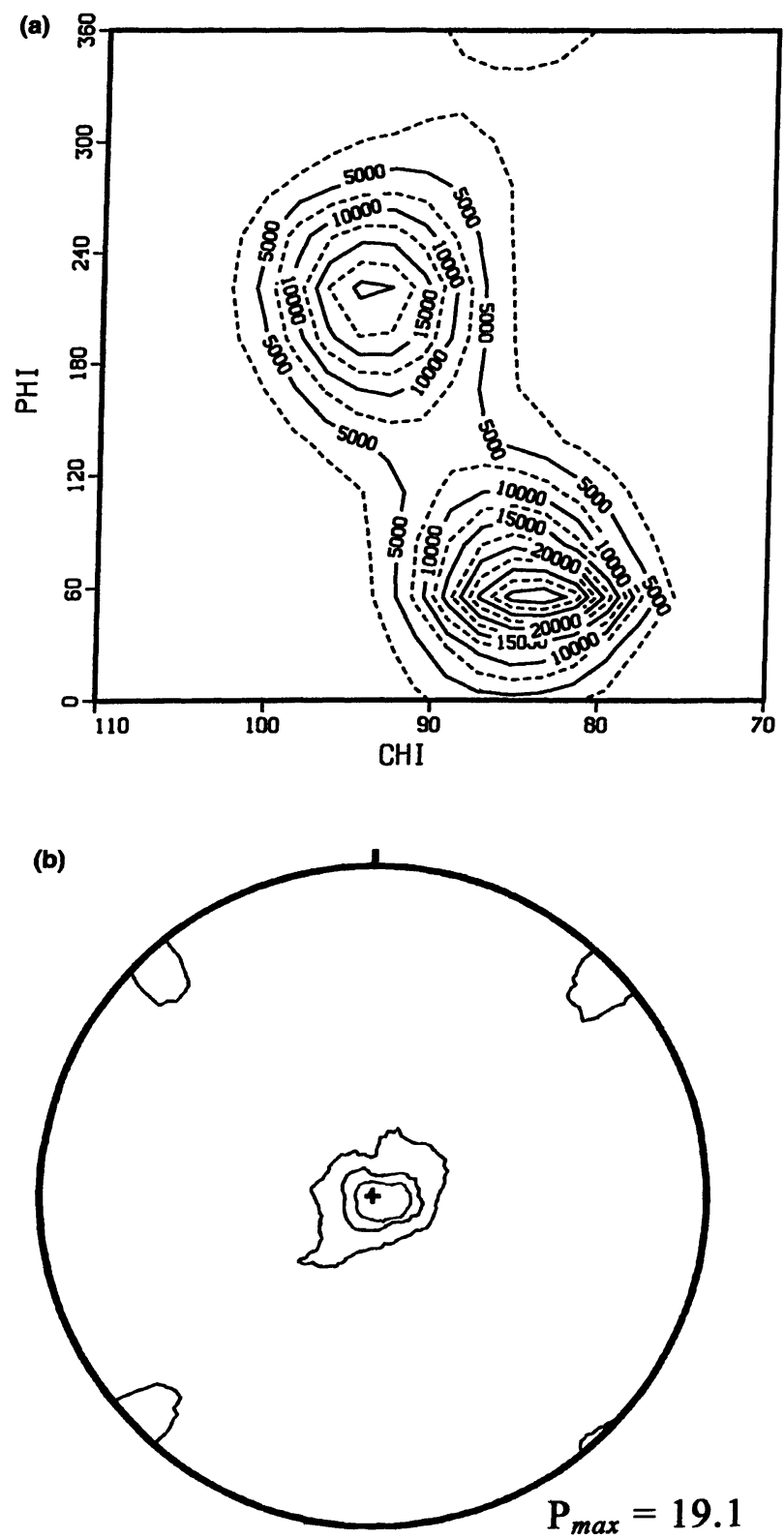

FIGURE 8 (a) Partial (005) pole figure of a melt grown YBaCuO-cylinder (phi $=0^{\circ}$ and chi $=90^{\circ} \rightarrow$ center of the pole figure). (b) (002) Pole figure of a YBaCuO-cylinder (45 mm diameter, $15 \mathrm{~mm}$ height) (contour levels 1.0, 5.0, 10.0, 15.0). 
cylinder was carried out to investigate the influence of the seed crystal on the texture homogeneity. The basic idea is to configure a set of seed crystals to produce an $\mathrm{YBaCuO}$-ring having an optimized texture and an optimized magnetic levitation force.

Example 2: Zinc on steel The investigation of relatively large sample volumes combined with a method of minor corrections allows the measurement of low volume fractions. One of these examples was the measurement of galvanized zinc on steel. Quadratic sections of a $0.7 \mathrm{~mm}$ steel sheet coated with $8-10 \mu \mathrm{m}$ zinc were cut. Thereafter a cubic sample of $12 \times 12 \times 12 \mathrm{~mm}^{3}$ was compacted to get a 'neutron sample' of $1728 \mathrm{~mm}^{3}$ which consists of $98.6 \mathrm{vol} \% \mathrm{Fe}$ and $1.4 \mathrm{vol} \% \mathrm{Zn}$. Simultaneously the bulk texture of zinc and iron were measured. Figures 9(a) and 9(b) show the recalculated pole figures of $\mathrm{Zn}(002)$ and $\mathrm{Fe}(110)$ using the series expansion method. For more details of this investigation see Brokmeier (1993).

Example 3: $\mathrm{AgBr}-\mathrm{AgCl}-\mathrm{Ag}$ The basic idea of this silver-halide composite was to use the optical properties in the mid-infrared region (MIR-fibers). On one hand the technique to produce such fibers had to be developed and on the other hand a non-destructive method to control the crystallographic texture particular of the $\mathrm{AgBr}$ core had to be applied. In the case of neutron diffraction three main problems

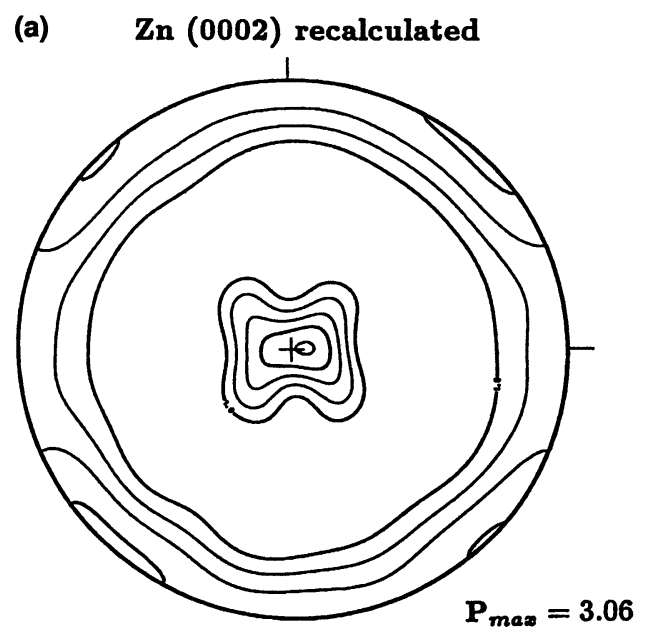

FIGURE 9(a) 


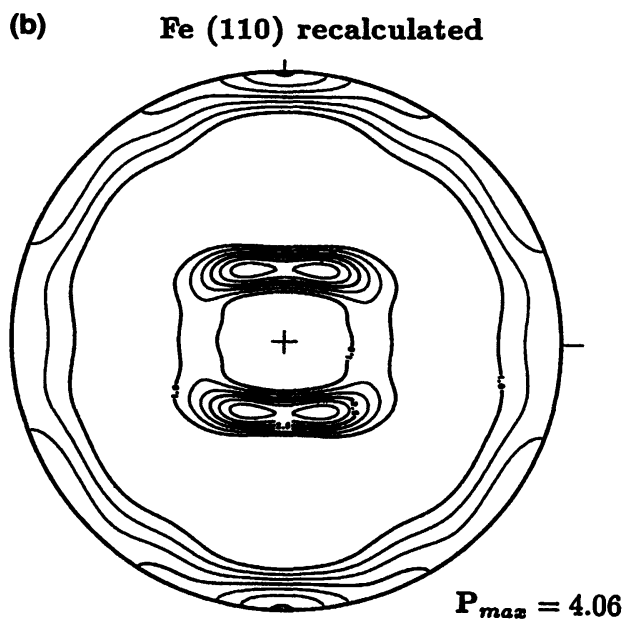

FIGURE 9 (a) Recalculated $\mathrm{Zn}(002)$ pole figure of a 8-10 $\mu \mathrm{m} \mathrm{Zn}$ coating on steel. (b) Recalculated $\mathrm{Fe}(110)$ pole figure of a steel coated by $8-10 \mu \mathrm{m} \mathrm{Zn}$.

TABLE $\mathrm{V}$ Characteristics of the $\mathrm{Ag}-\mathrm{AgCl}-\mathrm{AgBr}$ samples

\begin{tabular}{llccr}
\hline Sample & \multicolumn{1}{c}{ Phase } & $\begin{array}{c}\text { Diameter } \\
(\mathrm{mm})\end{array}$ & $\begin{array}{c}\text { Thickness } \\
(\mathrm{mm})\end{array}$ & $\begin{array}{c}\text { Vol. fraction } \\
(\%)\end{array}$ \\
\hline Extruded & Total & 7.6 & - & 100 \\
& AgBr core & 5.0 & - & 42 \\
& $\mathrm{AgCl}$ & - & 2.6 & 58 \\
Cold drawn & Total & 3.0 & - & 100 \\
& $\mathrm{AgBr}$ core & 2.51 & - & 77 \\
& $\mathrm{AgCl}$ & - & 0.18 & 3 \\
& $\mathrm{Ag}$ & - & 0.31 & 20 \\
Annealed & Total & 3.0 & - & 100 \\
& $\mathrm{AgBr}$ core & 2.51 & - & 70 \\
& $\mathrm{AgBr} / \mathrm{AgCl}$-gradient & - & 0.18 & 10 \\
& $\mathrm{Ag}$ & - & 0.31 & 20 \\
\hline
\end{tabular}

must be solved. First is the relatively high attenuation of silver, second is the low volume of the thin fibers and third is the overlapping of a number of reflections. Table $\mathrm{V}$ gives a summary of the sample characteristics after extrusion, cold drawing and annealing. For details of the graded fiber production and of the texture measurement see Böcker et al. (1995).

Figure 10 shows the inverse pole figures of the extruded material, the first step in the processing line. The calculations were performed using the iterative series expansion method ISEM (Dahms and Bunge, 1989). 

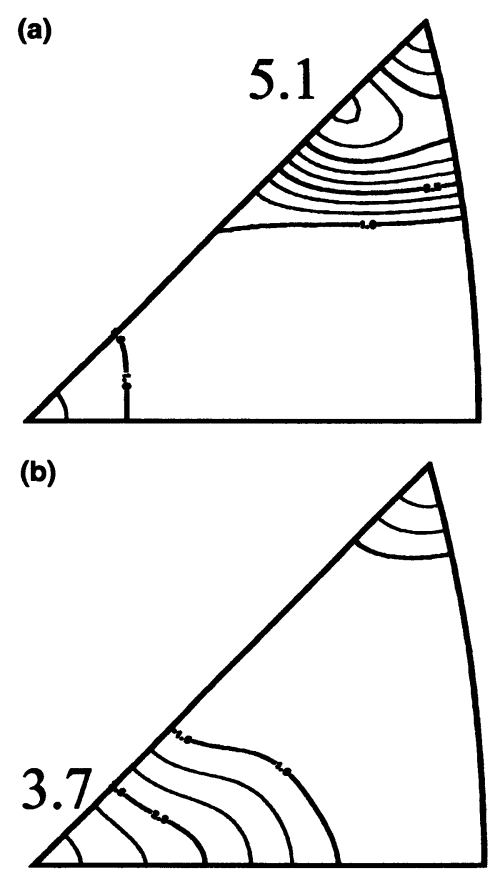

FIGURE 10 Inverse pole figures of extruded $\mathrm{AgCl}-\mathrm{AgBr}$ in extrusion direction: (a) $\mathrm{AgCl}$; (b) $\mathrm{AgBr}$.

ISEM allows on one hand to reduce the number of pole figures which are needed for an ODF calculation and on the other hand to separate overlapping reflections.

\section{CONCLUSIONS}

It can be summarized that neutron diffraction texture analysis has been developed to the standard method in bulk texture analysis. This is due to the high penetration of neutrons. Consequently the advantages are directly connected to the high penetration such as the investigation of coarse-grained materials, the measurement of complete pole figures, the neglection of surface roughness in sample preparation, the nondestructive texture measurement of non-uniform samples and the investigation of multi-phase systems. Potential candidates for neutron texture analysis are all geological materials. But also in materials science 
a number of applications need, up to now, neutron diffraction using high penetration. Future developments will lead to a combination of the usage of high energetic X-rays and neutrons to study bulk materials. High energetic X-rays are excellent in the study of local textures of a bulk material while neutron diffraction has still some advantages in the average texture of the bulk.

The main disadvantage of neutron diffraction as well as of high energetic $\mathrm{X}$-ray diffraction against conventional techniques is the radiation source. Owing to the limited number of sources and of course to the limited number of dedicated instruments open for texture analysis the application will be restricted.

\section{Acknowledgments}

A very special thank is directed to Prof. H.J. Bunge who is promoting neutron texture analysis since a long time. The author would like to thank the GKSS-Research Center Geesthacht GmbH for the excellent cooperation in the field of neutron texture analysis particular the whole FRG-1 team running the reactor more than 230 days every year. This work has been funded by the German Ministry for education, science, research and technology (BMBF) under the contract number 03 BR4CLA9.

\section{References}

Bacon, G.E. (1975), Neutron Diffraction, Clarendon Press, Oxford.

Böcker, W., Brokmeier, H.-G. and Bunge, H.J. (1995), Textures Microstruc. 24, 239-254. Bornemann, H.J., Brokmeier, H.-G., Burghardt, T., Hennig, W., Jung, V. and Zink, U. (1996), Proceedings of ICOTOM 11, Intern. Acad. Publishers, Beijing, pp. 951-956.

Brockhouse, B.N. (1953), Can. J. Phys. 31, 339-355.

Brokmeier, H.-G. (1993), Textures Microstruc. 21, 71-78.

Brokmeier, H.-G. (1994), Mat. Sci. Forum 157-162, 59-70.

Brokmeier, H.-G. (1995), GKSS-Report 95/E/9.

Brokmeier, H.-G and Bunge, H.J. (1987), Z. Krist. 178, 36.

Bunge, H.J. (1969), Mathematische Methoden der Texturanalyse, Akademie Verlag, Berlin. Bunge, H.J. (1989), Textures Microstruc. 10, 265-308.

Bunge, H.J., Wenk, H.-R. and Pannetier, J. (1982), Textures Microstruc. 5, 153-170.

Cullity, B.D.(1956), Elements of X-Ray Diffraction, Addison-Wesley Publishing Company Inc, London.

Choi, C.S., Prask, H.J. and Trevino, S.F. (1979), J. Appl. Cryst. 12, 327-331.

Dahms, M. and Bunge, H.J. (1989), J. Appl. Cryst. 22, 439-447.

Elf, F., Schäfer, W., Höfler, S. and Will, G. (1990), Textures Microstruc. 13, 55-58. 
Ewald, J.P. (1986), Theses Universität Hannover.

Feldmann, K. (1989), Textures Microstruc. 10, 309-324.

Hansen, N., Leffers, T. and Kjems, J.K. (1981), Acta Met. 29, 1523-1533.

Jansen, E.M., Brokmeier, H.-G. and Siemes, H. (1995), Textures Microstruc. 26-27, 167-179.

Juul Jensen, D. (1992), Neutron News 3, 20-23.

Matthies, S., Vinel, G. and Helming, K. (1987), Standard Distribution in Texture Analysis, Akademie Verlag, Berlin.

Schaeben, H. (1988), Phys. Stat. sol. (b) 148, 63-72.

Szpunar, J. (1976), Atomic Energy Rev. 14, 199-261.

Tobisch, J. and Bunge, H.J. (1972), Texture 1, 125-127.

Welch, P.I. (1986), In: Experimental Techniques of Texture Analysis. Eds. H.J. Bunge, DGM-Informationsgesellschaft Oberursel, 257-283.

Wenk, H.-R., Vergamini, P.J. and Larson, A.C. (1988), Textures Microstruc. 8/9, 443-456. 